\title{
NORMAS, SABERES E PRÁTICAS DOCENTES E A FORMAÇÃO DE PROFESSORES PARA A ESCOLA PÚBLICA PRIMÁRIA EM SÃO PAULO NO INÍCIO DO SÉCULO XX
}

\author{
Rosane Michelli de CASTRO ${ }^{1}$ \\ Elieuza Aparecida LIMA ${ }^{2}$
}

RESUMO: Neste artigo, buscamos apresentar aspectos sobre as normas, saberes e práticas docentes prescritos para a formação de professores para a escola primária em São Paulo no início do século, contidos nos Annuarios do Ensino do Estado de São Paulo mediante análise documental e histórica dos discursos das autoridades da instrução pública paulista. O método adotado foi o de análise do conteúdo. Concluiu-se que tais discursos retratam preocupações de época com a possibilidade de uma revisão dos "padrões tradicionais" de ensino e com a institucionalização de "um padrão científico" para se moldar obras futuras destinadas às escolas públicas do estado.

PALAVRAS-CHAVE: Educação. História da educação. Formação de professores. Normas, saberes e práticas. Annuarios do ensino do estado de São Paulo.

\section{Introdução}

No final do século XIX e primeiras décadas do século XX, a demanda pelas escolas normais e complementares no estado de São Paulo, voltadas para a formação do professorado, foi maior que a demanda pelos ginásios estaduais. As escolas normais e complementares públicas constituíram-se à época em uma opção atrativa à população, mormente à dos filhos e filhas de imigrantes, à de baixa renda e/ou com poucas chances de acesso ao ensino superior, como a feminina, que via nessas escolas uma das únicas oportunidades para obtenção de um nível de escolaridade mais elevado.

Particularmente entre os anos de 1909 e 1920, tal demanda gerou preocupações por parte do Governo do Estado. Segundo Tanuri (1979), em 1917 o Governo do Estado enviou uma mensagem ao Congresso Legislativo alertando para o fato de que o sistema de ensino primário não estava conseguindo absorver o excessivo número de professores formados anualmente.

\footnotetext{
${ }^{1}$ Doutora em Educação. UNESP - Universidade Estadual Paulista. Pós-Doutora pela Fundação Carlos Chagas. Atuando no Programa de Pós-Graduação em Educação. Professora Assistente. UNESP Universidade Estadual Paulista. Faculdade de Filosofia e Ciências. Marília - SP - Brasil. 17525-900 rosanemichelli@marilia.unesp.br.

${ }^{2}$ Doutora em Educação. UNESP - Universidade Estadual Paulista. Professora do Departamento de Didática e do Programa de Pós-Graduação em Educação. UNESP - Universidade Estadual Paulista Faculdade de Filosofia e Ciências. Marília - SP - Brasil. 17525-900 - elislima@ig.com.br.
} 
Na verdade, havia outra grande preocupação por parte do Governo do Estado de São Paulo com o exercício de um controle mais restrito, no sentido de que as escolas de formação de professores mantivessem o padrão de formação idealizado pelos primeiros reformadores republicanos, sobretudo na Escola Normal da Capital, tido como padrão de formação do professorado primário.

Assim, a fim de que o projeto oficial para a formação de professores da instrução pública continuasse hegemônico nas escolas normais, era preciso que as prescrições normativas ditadas pelas autoridades fossem incorporadas pelos normalistas e, sobretudo, que as escolas normais mantivessem-se no centro da cultura profissional do professorado como instituições a serviço das urgências sociais, políticas e administrativas, e símbolo da modernização do país, como acreditavam os primeiros republicanos.

Nesse processo, as tidas autoridades da instrução pública paulista ressaltaram o papel do professor para o país: “[...] não se deve esquecer nunca que o futuro de um país depende muito do professor público primário." (SÃO PAULO, 1914, p.13).

A relutância por parte das autoridades da instrução pública paulista em fazer das escolas normais, particularmente da Escola Normal da Capital o centro de formação dos educadores para todo o país, foi evidenciada no discurso pronunciado por Olavo Bilac aos alunos da Escola Normal da Capital:

\footnotetext{
Deste horto de energias e estudos, têm saído centenares e centenares de mudas viçosas, que, transplantadas do viveiro natal, foram florescer e frutificar nas cidades e povoações que esmaltam a forte e bela terra de São Paulo; e, honra mais alta par vós, os Governos de outros Estados vêm procurar aqui educadores para a sua gente [...]. (SÃO PAULO, 1917, p.210).
}

Aos discursos de exaltação do trabalho desenvolvido nas escolas normais juntaram-se aqueles que indicavam as tidas "deficiências" dessas escolas, responsáveis pelo que era considerada "má formação" do professorado público primário paulista, cujas atenções das autoridades da instrução, como a de João Chrysostomo, voltaram-se em maior proporção:

Os conhecimentos práticos com que os nossos professores saem das Escolas Normais não os habilitam à regência de uma escola ou de uma classe de grupo. Salvo algumas exceções, incertos e sem nenhuma firmeza, vão por muitos meses e, quiçá, por alguns anos, 
completamente às escuras, tateando no caminho a seguir das várias disciplinas do curso. A prática adquirida nos cursos anexos é insuficiente para a regência de classe a seu cargo. Precisam, portanto, ao iniciar sua carreira, de bons guias e estes, pela deficiência de tempo e por outras causas, ele não os encontra nos diretores dos grupos em que vão servir, ou nos inspetores escolares. É preciso que se lhes forneçam leituras apropriadas, bons manuais de ensino, conselhos, ensinamentos diversos, de modo que eles se façam professores na lata extensão da palavra, capazes de se aviarem com aptidão e desembaraço, não somente na regência de suas classes, senão também nas suas relações com os seus superiores hierárquicos, com os pais dos alunos, com o meio social em que vão viver. (SÃO PAULO, 1916, p. 14).

A vasta quantidade de discursos acerca das "deficiências" da formação do professorado teria atuado como um mecanismo de mobilização dos professores paulistas com o intuito de fazer com que estes apoiassem os projetos das autoridades na esfera da instrução pública. Consequentemente, as autoridades da instrução pública paulista buscaram a legitimação de suas próprias intervenções prescritivas e mantenedoras de normas, saberes, práticas e instituições que funcionaram como mecanismos para a ordenação dos processos de formação e de atuação do professorado paulista.

Assim, à luz do que aqui denominamos de "motivos" legitimados nos discursos das autoridades da instrução paulista, no presente artigo a busca foi por evidenciar aspectos resultantes da leitura dos ideais escolanovistas, motivada pela urgência de controle e uniformização das escolas e do professorado público primário paulista, nas primeiras décadas do século XX. Grande parcela desses "motivos" encontram-se materializados discursivamente nos periódicos que circularam à época, dentre os quais, os Annuarios do Ensino do Estado de São Paulo.

Publicados, entre os anos de 1907 e 1927 e, posteriormente, alguns números na década de $1930^{3}$, os Annuarios do Ensino do Estado de São Paulo constituíram-se à época em que circularam num importante periódico representativo de um universo

3 “Após 1927, foi publicado um 'Relatório' referente ao período de 1927-1928, última publicação oficial do conjunto sobre a administração da instrução pública paulista da década de 1920. Em 1931, a Diretoria Geral do Ensino do Estado de São Paulo, tendo à frente o professor Lourenço Filho, editou um volume contendo a estatística escolar de 1930 e, em 1937, Almeida Júnior, então Diretor de Ensino, organizou o anuário de 1935-1936 referente à administração do ensino primário e pré-primário (estadual, municipal e particular), do ensino secundário estadual e do ensino normal (estadual e livre) em 1935 e 1936." (CASTRO, 2012, p.213). 
imaginário ${ }^{4}$ acerca da instrução pública paulista ${ }^{5}$ construído pelas "altas autoridades do ensino do estado de São Paulo" e, ao mesmo tempo, num mecanismo de mitificação de novas práticas e posturas disciplinares a serem incorporadas prioritariamente pelo professorado público primário. Utilizamo-nos do termo mitificação com o objetivo de enfatizar o quanto os discursos contidos nos anuários em estudo tentaram impor-se como os representantes das "verdades" a serem aceitas e seguidas, acerca da situação da instrução pública no estado de São Paulo.

Enfim, é possível definir os Annuarios do Ensino do Estado de São Paulo como periódico veiculador de um universo específico de opiniões sobre a instrução pública, orientadas para a compreensão e o domínio do campo educacional à lógica do poder oficial, o que possibilita a sua tomada como um conjunto de representações coletivamente construídas a partir de uma orientação específica. ${ }^{6}$

Trata-se, portanto, de artigo resultante de uma pesquisa histórica e documental quanto às fontes (CASTRO, 2000), cujo método adotado foi o de análise do conteúdo, e cujas etapas previstas organizaram-se em três momentos cronológicos: a pré-análise (reunião e seleção dos números dos Annuarios do Ensino do Estado de São Paulo) que contêm os discursos de prescrição de modelo de prática de ensino); a fase inicial (categorização e análise dos discursos); e, a fase final (interpretação dos discursos).

\section{As escolas públicas paulistas, segundo uma leitura particular das "altas autoridades" sobre as ideias escolanovistas}

Segundo Tanuri (1979), a Primeira Guerra Mundial (1914-1918) teria colocado em evidência no Brasil, tal qual acontecia nos países da Europa e nos Estados Unidos, a necessidade de se rever o ensino, "[...] em seus princípios e instituições, a fim de que fosse constituído, segundo pensava-se, o mais sólido alicerce para a manutenção da paz e compreensão entre os homens." (TANURI, 1979, p.153). Como consequência disso, também no Brasil foram introduzidos, conforme Lourenço Filho (apud TANURI, 1979), os princípios e as práticas da educação renovada no ensino público. Já no anuário de

\footnotetext{
${ }^{4} \mathrm{O}$ universo imaginário está aqui sendo tomado da mesma forma como o concebe Orlandi (1994), ou seja, por meio da sua capacidade de constituir-se em referencial de sustentação das representações em nível subjetivo.

${ }^{5}$ A expressão "instrução pública" é a denominação própria da época dada à esfera do que conhecemos hoje como ensino público. Assim, no decorrer de todo o presente trabalho será utilizada tal expressão.

${ }^{6}$ Entende-se aqui por representações, as "[...] estratégias de pensar a realidade e construí-la [...]", tal como explicita Souza (1998, p.18).
} 
1917, Thompson (SÃO PAULO, 1917, p.7) mostrou-se sensível com as possíveis dimensões que tais práticas e princípios pudessem adquirir entre o professorado público paulista, uma vez que o movimento da escola nova centrou-se, notadamente, conforme Tanuri (1979, p.154), “[...] na revisão dos padrões tradicionais de ensino, ou seja, dos programas escolares, dos métodos didáticos, do processo ensino-aprendizagem, dos papéis do professor e aluno", até então regulados pelo restrito grupo das autoridades da instrução pública.

Escola nova, para nós, é a formação do homem, sob o ponto de vista intelectual, sentimental e volitivo; é o desenvolvimento integral desse trinômio psíquico; é o estudo individual de cada aluno; é, também, o ensino individual de cada um deles, muito embora em classes; é a adaptação do programa a cada tipo de educando; é a verificação das lacunas do ensino do professor pelas sabatinas e exames; é o emprego de processos especiais para a correção profissional, caminhando, paralelamente, com o desenvolvimento mental da criança; é a preparação para a vida prática; é a transformação do ambiente escolar num perene campo de experiência social; é a escola de intensa vida cívica, do cultivo da iniciativa individual, do estudo vocacional, da difusão dos preceitos de higiene, e, principalmente, dos ensinamentos da puericultura; é, em suma, a escola brasileira, no meio brasileiro, com um só lábaro: formar brasileiros, orgulhosos de sua terra e de sua gente.

[...]

As últimas descobertas da nova psicopedagogia inverteram, no ensino, o papel do professor e o do aluno. O professor que falava para o aluno ouvir; que pensava pelo aluno; que aferia toda a classe pelo mesmo nível intelectual e a julgava capaz de acompanhá-lo com o mesmo aproveitamento, há de ser substituído pelo professor que ouve o que o aluno diz; que provoca o seu raciocínio; que considera, como unidade psíquica, sob o ponto de vista intelectual, moral e volitivo; que descobre, através de seus trabalhos gráficos ou orais, os defeitos e as falhas do seu ensino e procura dar exercícios apropriados a cada tipo de aluno e não à classe. $\mathrm{O}$ ensino tende, tanto quanto possível, a individualizar-se, adaptando-se a cada aluno os métodos e programas. [...]

Quanto à pedagogia social, precisamos convir que a educação, no Estado, não pode ter os mesmos moldes e fins absolutamente idênticos em toda a parte, devido à sua grande extensão territorial. A da zona urbana, mais esclarecida e mais exigente, quanto à extensão do ensino, requer melhores e mais aperfeiçoados aparelhos escolares.

Pode-se dizer que ela está feita, porque não há localidade, em São Paulo, que não tenha, segundo a sua importância, um ou mais Grupos Escolares, ou, simplesmente, escolas. Há ainda na mesma zona três ginásios, três escolas profissionais, onze escolas normais, além da Escola Agrícola de Piracicaba, subordinada à Secretaria da Agricultura, e outras casas de ensino superior.

A educação, aí, apresenta, pois, uma outra feição pedagógica, diferente da do povo, que habita a zona marítima e o chamado Nordeste de São Paulo, cuja população rural, constituída, quase 
exclusivamente, de descendentes de caboclos que se dedicam ao amanho da terra, precisa ter escolas que cuidem, primordialmente, de afastar as causas do seu abatimento moral; levantar-lhes o caráter; darlhes hábitos de trabalho e fazer a propaganda dos novos processos de agricultura.

Nas zonas Oeste e Nordeste, cuja população rural é, na sua grande maioria, descendente de estrangeiros, a principal preocupação da escola deve ser o ensino da língua, como primeiro fator de assimilação, e o conhecimento dos homens e da terra brasileira. (SÃO PAULO, 1917, p.7).

Como é possível observarmos, no anuário de 1917 as construções discursivas de Thompson (SÃO PAULO, 1917, p.7) sobre os aspectos fornecidos pelo "movimento escolanovista", trouxeram, em contiguidade, os objetivos sociais para a instrução pública, formulados mediante as diretrizes nacionalistas e conforme os intuitos do governo estadual paulista, objetivos esses de extensão a todos os cidadãos de escola pública primária, como instrumento de defesa da nacionalidade e de integração entre brasileiros das mais diversas regiões, na vida nacional. Tratou-se de uma revisão dos padrões das escolas públicas vigentes até então, a partir de uma leitura particular das autoridades da instrução pública, sobre as ideias escolanovistas.

\section{Normas, saberes e práticas para o trabalho cotidiano do professorado}

A intensidade das preocupações com a possibilidade de uma revisão dos tidos "padrões tradicionais" de ensino, inevitável diante da difusão das ideias de renovação escolar, também foi evidenciada mediante as construções discursivas dos anuários, de uma comissão chamada a analisar os livros didáticos que deveriam ser utilizados nas escolas de ensino primário e, sobretudo, por meio daqueles discursos sobre os requisitos sob os quais seria instituído "[...] um padrão científico, por onde se pudessem moldar as obras futuras, destinadas às escolas [...]" (SÃO PAULO, [1919?], p.142). A comissão foi composta por Antônio de Sampaio Dória, Américo de Moura e Plínio Barreto.

Dentre os discursos dessa comissão, foram expostos três requisitos eleitos para atuar no processo seletivo dos livros didáticos, a saber: a propriedade do assunto, a didaticidade ou método de desenvolvimento do assunto e linguagem utilizada. Os referentes a este último refletiam, diretamente, as preocupações do pós-guerra, pois, em função de despertar o espírito de patriotismo, recomendou-se evitar, no que dizia respeito à linguagem dos livros didáticos, os solecismos e os estrangeirismos, uma vez 
que, caso insinuassem na alma infantil, concorreriam "[...] mais que tudo, para a desnacionalização e deturpação do enérgico e meigo idioma de nossos maiores" (SÃO PAULO, [1919?], p.143).

Finalmente, Sampaio Dória, Américo de Moura e Plínio Barreto prescreveram um padrão por onde deveriam se moldar as obras didáticas:

Linguagem progressivamente enriquecida, correta, clara, sóbria e elegante. Assunto acessível ao entendimento das crianças, e não menos capaz de lhes concorrer para a formação da mentalidade e do caráter. Condições tipográficas de saúde visual e de agrado, método na movimentação de assuntos, segundo as leis que disciplinam o fenômeno do conhecimento. As obras, que não se subordinarem a esta orientação, sobre não valerem o papel em que se imprimem, são prejudiciais ao ensino. Porque não só deixam de ensinar e educar, com eficácia, como vão insinuando, no espírito infantil, o aborrecimento pelas boas leituras. (SÃO PAULO, [1919?], p.147).

Datados de janeiro de 1918, tais construções discursivas descreveram minuciosamente cada uma das etapas do processo que originou uma relação única de livros, mormente as análises e os pareceres de cada um dos três integrantes da referida comissão. Além disso, juntamente com a relação de livros eleita foi veiculada uma orientação metódica sobre como os professores deveriam proceder no seu trabalho cotidiano com o referido material, além das indicações dos livros de leituras suplementares e auxiliares e demais materiais didáticos.

Foram estas as obras que, com todas as suas deficiências, nos pareceram preferíveis:

$1^{\circ}$. Para a aprendizagem da leitura, o Meu Livro de Theodoro de Morais, Cartilha Infantil de Gomes Cardim, Cartilha Analíticosintética de Mariano de Oliveira.

$2^{\circ}$. Para a leitura no primeiro ano, o Primeiro Livro de João Köpke. São 66 lições que os pequenos escolares não podem vencer com proveito, senão no dobro ou triplo de aulas correspondentes. Basta considerar que, no ensino da linguagem, nenhum professor agirá com proficiência, senão, primeiro, narrando a história da lição; procedendo, depois, ao exame das palavras mais difíceis, mediante frases que escreve no quadro negro; ordenando, em seguida, uma leitura silenciosa por toda a classe; encaminhando, após, a leitura expressiva, em que um em vários alunos leiam sucessivamente trechos da mesma história nos diálogos, conforme as necessidades; e por fim, tirando, com explicações adequadas, todo o proveito que os ensinamentos da lição comportarem. O tempo gasto com todo este trabalho esgota, com o necessário à aprendizagem da leitura, todo o ano letivo. Se, contudo, alguma classe houver de notável precocidade, ou extraordinário adiantamento, que chegue ao fim do livro com proveito, antes de 
terminado o ano letivo, o recurso será laçar mão de um outro livro de leitura. Para esta hipótese, adiante se exara uma lista de livros aproveitáveis, entre os quais pode cada professor, com inteira liberdade, escolher o que pareça mais conveniente à classe que dirige. $3^{\circ}$. Para a leitura no segundo ano, o Segundo Livro de João Köpke. Ainda que o professor saiba, no processar a leitura, ter aquele vagar que é segredo da pressa em todas as coisas humanas, algum tempo ainda terá para outras leituras no segundo ano. Convém que o professor fique com a iniciativa de adotar, entre os livros da lista suplementar adiante registrados, um ou dois que julgar mais adequados ao preparo e capacidade dos seus alunos. Os interesses mesmos do ensino aconselham esta liberdade, tanto mais quanto todos os livros, entre os quais ele pode escolher, ficam aprovados oficialmente para este fim. É indispensável a escolha pelo menos de um, para que possam os alunos seguir, com proveito, o terceiro livro do ano seguinte.

$4^{\circ}$. Para a leitura no terceiro ano, o Terceiro Livro de João Köpke. Aqui e sempre, a eficácia do ensino exige uma certa iniciativa e liberdade do professor, para suprir, com livros bons, as necessidades que verificar. A lista dos livros suplementares, abaixo indicados, lhe dará possibilidade de uma seleção apropriada.

$5^{\circ}$. Para a leitura do quarto ano, o livro de leitura que o professor achar melhor na lista suplementar, e Através do Brasil, de Olavo Bilac e Bonfim, e mais os livros necessários ao bom desempenho dos programas, tirados desta lista que segue:

$6^{\circ}$. Para leituras suplementares e auxiliares, Poesias Infantis de Olavo

Bilac, Leituras Preparatórias de Rita $\mathrm{Macedo}^{7}$, Leituras Preparatórias de F. Vianna e Miguel Carneiro, Contos Infantis de Júlia Lopes, Fábulas de Justiniano da Rocha, Páginas Infantis de Mariano de Oliveira, Cousas Brasileiras de Puiggari-Barreto, Páginas Infantis de P. de Almeida, Contos Infantis de Júlia Lopes, Alma Infantil de Francisca Júlia, Histórias de Nossa Terra de Júlia Lopes, Contos Práticos de Coelho Netto e Olavo Bilac, Nossa Pátria de Rocha Pombo, Contos Morais e Cívicos, de C. Góes, Leituras Morais de Arnaldo Barreto, Biblioteca Infantil organizada por Arnaldo Barreto, Minha Pátria de Pinto e Silva, Pequenos Trechos de Otaviano de Mello, Leituras Práticas de João Köpke, Leituras Manuscritas de B.P.R., Moral Prática Elementar de Emília Costa, Don't, Meu Livro de Theodoro de Moraes, Livros de Leitura $\left(1^{\circ}, 2^{\circ} \mathrm{e}\right.$ $\left.3^{\circ}\right)$ de Puiggari-Barreto, Segundo e Terceiro Livro de Galhardo, Primeiro, Segundo e Terceiro Livro de Francisco Vianna, Novas Leituras de Roca e M. Oliveira $\left(1^{\circ}, 2^{\circ}\right.$ e $\left.3^{\circ}\right)$, Coração das Crianças de Rita Macedo, Palestras Sobre as Plantas de C. Brilho, Leituras Intermediárias de Maria Rosa.

$7^{\circ}$. Os demais livros e material didático com exceção dos Quadros de Linguagem de M.B. Roca, dos Mappas de Parker, dos Cadernos de Aritmética de R. Roca e do Desenho Profissional de Aprígio Gonzaga, os primeiros para cooperar com o ensino de aritmética nas escolas preliminares, e o terceiro para auxiliar o desenho nas escolas primárias profissionais, foram rejeitados. Uns, por não valerem nada; outros, por estarem acima da compreensão infantil, alguns por excessivos pecados didáticos, muitos por não terem aplicação, como todos os compêndios

${ }^{7}$ Esta mesma autora aparece com o nome de Rita Barreto em um resumo desta mesma lista feita pela mesma comissão, à página 185 do mesmo anuário. 
de aritmética, de geografia, de história, de geometria, de física, de história natural, cadernos de caligrafia, de cartografia, cartonagens, modelos de trabalhos manuais. Ao professor compete o ensino vivo destas matérias, sempre fiel à intuição com o seu princípio de atividade do educando, com a cooperação educadora e orientadora do mestre, com a marcha necessariamente analítica, e o contato das realidades que se pretende ensinar às crianças, o contato das coisas em si, ou figuradas, com a inteligência dos estudantes. Numeroso material para o ensino destas matérias só serve para enfastiar o professor e aborrecer os alunos. (SÃO PAULO, [1919?], p.148).

Além dos livros didáticos a serem utilizados nas escolas primárias, sob o signo de promover a uniformidade da atividade docente nos vários estabelecimentos de ensino primário mantidos pelo Estado, João Lourenço Rodrigues sugeriu, logo no anuário de 1907-1908 ([1908]), a existência de diferentes mecanismos para controlar o processo de formação e de aperfeiçoamento do professorado público primário, do seu trabalho e comportamento profissional, como: orientações, palestras e reuniões pedagógicas, leitura de periódicos como as próprias publicações dos anuários e a criação e manutenção de bibliotecas estaduais:

\begin{abstract}
Por mais notório que seja a dedicação dos professores, eles vivem, como se costuma dizer, au jour le jour, dispondo apenas do tempo preciso para a preparação diária das lições, sem folga que lhes permita seguir através dos livros e revistas especiais o movimento pedagógico do país e os melhoramentos progressivos da arte de ensinar. (SÃO PAULO, [1908], p.10).

O segundo meio de que a Inspetoria lançará mão se as circunstâncias o permitirem, será a publicação de um Anuário do Ensino, onde os professores possam encontrar, a par de uma boa estatística e do movimento escolar de todo o Estado, uma colaboração abundante e variada sobre a parte técnica do ensino, os métodos empregados e seus resultados práticos. (SÃO PAULO, [1908], p.17).

[...] a falta em muitos professores, de uma orientação pedagógica [...] para que o professor esteja a par desses melhoramentos e deles tire partido, necessário é que exista uma fonte de informações de fácil acesso que o exonere da tarefa de longas leituras para as quais, aliás, lhe falta o tempo. (SÃO PAULO, [1908], p.30).

[...] pediu uma providencia no sentido de que em todos os grupos escolares, à semelhança do que antigamente era feito na primitiva escola modelo, os professores se reunam para a discussão dos melhores métodos e processos do ensino. (SÃO PAULO, [1908], p.400).
\end{abstract}

Assim também o fizeram: o Inspetor Escolar René Barreto, no anuário de 19091910 (SÃO PAULO, [1910]), João Chrysostomo Bueno dos Reis Junior, no anuário de 1914 (SÃO PAULO, [1915?]), Oscar Thompson, no anuário de 1918 (SÃO PAULO, 
[1919?]), Guilherme Kuhlmann e João Toledo, lente e Diretor da Escola Normal de Campinas, no anuário de 1920-1921 (SÃO PAULO, [1921?]):

Seria também necessário que alguma medida fosse tomada no sentido de facilitar aos professores a leitura de revistas, monografias e tratados de pedagogia, dos relatórios de instrução pública em diversos países, enfim duma literatura didática, que habilitasse a acompanhar todos os melhoramentos que vão sendo introduzidos no ensino europeu e das duas Américas. Parece-me que alguma coisa com esse fim podia fazer-se, bastando que em cada grupo escolar do interior do Estado o governo construísse uma pequena biblioteca [...] Quanto aos professores da Capital, aproveitar-se-iam da biblioteca que se fizesse na Diretoria Geral da Instrução Pública, a qual, sendo repartição técnica, até hoje se ressente da falta de uma biblioteca adequada, pois a que só agora lá existe é constituída por livros de propriedade particular do Sr. Dr. Diretor Geral. (SÃO PAULO, [1910], p.258).

Os meios, de que se devem lançar mão, são variados, e todo o ensino [nas escolas normais] deve concorrer para esse fim: - Reduzam-se as lições aparatosas; aumentem-se os trabalhos em que o aluno possa revelar estudo próprio, iniciativa, firmar sua individualidade; sejam excluídos os métodos, que não exercitam as faculdades ativas do espírito; multipliquem-se, principalmente no estudo das ciências, os contatos com a realidade; abonem-se os pormenores supérfluos, que sobrecarregam inutilmente a memória, e dêem-se aos alunos, em linhas gerais, indispensáveis para caracterizar cada ciência e liga-as umas às outras, que o ensino atuará poderosamente, não só desenvolvendo as faculdades intelectuais, mas também a ação e a vontade, e servindo de norma segura, que orienta na vida. (SÃO PAULO, [1915?], p.52).

Existem palestras (onde professores e alunos participam) onde os deveres e direitos em relação à coletividade é objeto de atenção a nossa carta republicana. Aí a eleição, o voto, o imposto, a formação de poderes constituem objeto de ensino, com a forma mais prática possível, servindo de exemplos a organização da família, da escola, das sociedades recreativas, etc., consideradas nos seus pontos análogos à organização do Estado. (SÃO PAULO, [1919?], p.364).

Tenhamos feito isso [reuniões] também e indaguemos do resultado da escola. Ainda não será apreciável. Por quê? Porque falta o principal aquilo que seria, só por só, a causa da deficiência da escola, o motivo do desanimo do professor - falta a aproximação dos professores das escolas isoladas, reunidos todos, ás autoridades a que estiverem sujeitos, mensalmente, afim de que palestrem sobre cousas do ensino e se estimulem pelas discussões que tiverem e se encorajem e se encham de alegria pela troca de ideias, com proveitoso resultado, troca que se aumentará a pouco e pouco. A não ser a visita do inspetor, nada mais resta ao professor de aproximação [...] seria de resultado bom, como meio de eficiência, uma reunião mensal dos professores das escolas isoladas, reunião que poderá se efetuar na diretoria dos grupos escolares, com o fim de cuidar de assumptos pedagógicos e próprios ao momento e ao lugar. (SÃO PAULO, [1921?], p.284).

A formação de uma 'biblioteca do professor primário' é uma necessidade que se impõe, como complemento indispensável a tudo 
quanto de bom se tem feito. Sem ela, os esforços dos dirigentes hão de perder-se por mais de dois terços". (SÃO PAULO, [1921?], p.361).

Atreladas a toda política de prescrição de livros de leitura e de orientação e controle metódico da utilização desse material didático pelo professor e de controle do processo de formação e de aperfeiçoamento do professorado público primário, estiveram ocasiões festivas e de lazer, às quais deveriam visar os mesmos objetivos, como sugeriu João Lourenço Rodrigues no bianuário de 1907-1908 (SÃO PAULO, [1908]):

Esta simpática solenidade efetuou-se pela primeira vez na Escola Normal, em 1906.

$[\ldots]$

Encerrou-se os festejos escolares a garden-party oferecida pelo governo aos professores e alunos das escolas isoladas da Capital.

Reunindo-se numa festa coletiva, foi esta a maneira atraente e expressiva de que se utilizou o governo para inculcar no espirito dos professores a certeza de que, isoladas quanto o tipo de sua organização, aquelas escolas devem formar pelo critério e esforço de quem as rege um aparelho harmônico e militante nas lides do ensino.

[...] a garden-party excedeu á expectativa de seus organizadores, sendo também certo que ao espirito dos mestres não passou despercebido o seu alcance moral [...]. (SÃO PAULO, [1908], p.63).

É possível afirmarmos que, também as ocasiões festivas e de lazer deveriam prestar-se a inculcar nos professores espírito de unidade de intuitos quanto à profissão que exerciam. Além disso, tais ocasiões, assim como em exposições nacionais e internacionais, foram utilizadas como meios para propagandear os feitos e as temáticas sobre educação que interessavam às autoridades da instrução pública.

\section{Algumas considerações finais}

Como observa-se, neste artigo buscamos apresentar aspectos sobre as normas, saberes e práticas docentes prescritos para a formação de professores para a escola primária em São Paulo no início do século, contidos nos Annuarios do Ensino do Estado de São Paulo mediante análise documental e histórica dos discursos das autoridades da instrução pública paulista, mais no sentido de somar, ainda que singelamente, a uma vasta produção sobre essa temática relevante para a história da educação brasileira. 
Visando manter a hegemonia de suas concepções educacionais, o Governo Estadual aliado às ideias dos intelectuais, educadores e políticos liberais utilizava-se das publicações dos Annuarios do Ensino do Estado de São Paulo para propagandear as suas ações intervencionistas no âmbito da instrução pública e garantir a sua imprescindibilidade nesse campo que desde a viragem do século ia autonomizando-se e constituindo-se enquanto um campo teórico e uma esfera administrativa próprios. Tal fenômeno pode ser comprovado por meio das informações contidas nesses anuários, principalmente as referentes às leis e decretos que anunciavam as alterações na legislação da instrução pública e as reformas educacionais de intensos investimentos, tanto no campo teórico como no campo administrativo. Como exemplo, temos que no anuário de 1918 (SÃO PAULO, [1919?]), encontram-se reunidas todas as disposições da Lei n. 1.579, de dezembro de 1917, que dispôs sobre as disciplinas que deveriam figurar nos programas das escolas distritais, rurais e urbanas, dos grupos escolares e cursos complementares.

Além do conjunto de prescrições apresentado neste artigo, é possível encontramos outras anunciadas por Thompson, também no anuário de 1918 (SÃO PAULO, [1919?]), com relação aos conteúdos a serem ensinados e os métodos e processos para o seu desenvolvimento. Movidos pelos mesmos objetivos de prescrição de conteúdos a serem ensinados, métodos e processos para o seu desenvolvimento na escola pública paulista, discursos de outras autoridades da instrução pública paulista juntaram-se aos de Thompson (SÃO PAULO, 1917) nos Annuarios do Ensino Público Paulista. A exemplo disso, Carlos Alberto Cardim, então Diretor da Escola Normal, prescreveu procedimentos a serem acompanhados pelos diretores das escolas normais para desenvolvimento dos programas das escolas-modelo pelos futuros professores primários (CASTRO, 2000).

Finalmente, observa-se, dentre outros aspectos, que a intensidade das preocupações com a possibilidade de uma revisão dos tidos "padrões tradicionais" de ensino, inevitável diante da difusão das ideias de renovação escolar, e a fim de que se fosse instituído “[...] um padrão científico, por onde se pudessem moldar as obras futuras, destinadas às escolas", foi evidenciada mediante as normatizações contidas nos anuários, enfaticamente no anuário de 1918 (CASTRO, [1919?]), dentre outras, para a adoção de livros para o ensino de leitura nas escolas primárias públicas de ensino primário. 


\section{NORMS, KNOWLEDGE AND TEACHING PRACTICES AND TEACHER TRAINING FOR THE PRIMARY PUBLIC SCHOOL IN SÃO PAULO IN THE EARLY TWENTIETH CENTURY}

ABSTRACT: In this article, we seek to present aspects about the norms, knowledge and teaching practices prescribed for the training of teachers for primary school in Sao Paulo in the early of the century, contained in the Annuarios Education of the State of São Paulo, through of analysis historical and documental of the discourses of the authorities of the paulists public instruction. The method used was the content analysis. It was concluded that such discourses portray the preoccupation with the possibility of a review of the "traditional standards" of teaching and with the institutionalization of "a scientific standard" to shape the future construction aimed at public schools in the state.

KEWORDS: Education. Education's history. The training of teachers. Norms, knowledge and practices.

\section{REFERÊNCIAS}

CASTRO, R. M. A história da educação em São Paulo: a instrução pública dada a ler nos Annuarios do Ensino do Estado de São Paulo - 1907-1927. Revista Brasileira de História da Educação, Campinas, v.12, n.2, p.209-238, mai./ago. 2012.

Vida e trabalho de professores primários: um estudo dos Annuarios do Ensino do Estado de São Paulo (1907-1927). Marília, 2000. 2 v. Dissertação (Mestrado em Educação) - Faculdade de Filosofia e Ciências, Universidade Estadual, Marília, 2000.

ORLANDI, E. P. Discurso, imaginário social e conhecimento. Em Aberto, Brasília, ano 14, n.61, p.53-59, jan./mar. 1994.

SÃo PAULO (ESTADO). Annuario do ensino do estado de São Paulo (1907-1908) (Publicação organizada pela Inspetoria Geral do Ensino por ordem do Governo do Estado). São Paulo: Augusto Siqueira \& C., [1908].

Annuario do ensino do estado de São Paulo (1909-1910) - (Publicação organizada pela Diretoria Geral da Instrução Pública por ordem do Governo do Estado). São Paulo: Tipografia do Diário Oficial, [1910].

Annuario do ensino do estado de São Paulo (1913) - (Publicação organizada pela Diretoria Geral da Instrução Pública por ordem do Governo do Estado). São Paulo: Tip. Siqueira, [1914].

Annuario do ensino do estado de São Paulo (1914) - (Publicação organizada pela Diretoria Geral da Instrução Pública por ordem do Governo do Estado). São Paulo: Tip. Siqueira, [1915?].

Annuario do ensino do estado de São Paulo (1915) - (Publicação organizada pela Diretoria Geral da Instrução Pública por ordem do Governo do estado). São Paulo: Augusto Siqueira \& C., [1916]. 
Annuario do ensino do estado de São Paulo (1917) - (Publicação organizada pela Diretoria Geral da Instrução Pública por ordem do Governo do Estado). São Paulo: Augusto Siqueira, 1917. v.1.

Annuario do ensino do estado de São Paulo (1918) - (Publicação organizada pela Diretoria Geral da Instrução Pública por ordem do Governo do Estado). São Paulo: Augusto Siqueira, [1919?].

Annuario do ensino do estado de São Paulo (1920-1921) - (Publicação organizada pela Diretoria Geral da Instrução Pública por ordem do Governo do Estado). São Paulo: Augusto Siqueira, [1921?].

SOUZA, R. F. Templos de civilização: a implantação da escola primária graduada no Estado de São Paulo (1890-1910). São Paulo: Ed. da UNESP, 1998.

TANURI, L. M. O ensino normal no estado de São Paulo: 1889-1930. São Paulo: FE/USP, 1979. (Estudos e Documentos, 16). 